\title{
STUDY OF HIGHER MODE EFFECTS AND LATERAL LOAD PATTERNS IN PUSHOVER ANALYSIS OF STEEL FRAMES WITH STEEL SHEAR WALL
}

\author{
Mohammad Ghanoonibagha', Mohammad Reza Ashrafi Gol'2, Mohammad Reza Ranjbar ${ }^{3}$ \\ Department of Civil Engineering, East Tehran Branch, Islamic Azad University, Tehran, Iran, e-mail: \\ ghanoonibagha@iust.ac.ir \\ 2 School of Civil Engineering, Iran University of Science and Technology, Narmak, Tehran, Iran \\ 3 Technical Faculty of Mapping, Zabol University, Zabol, Iran
}

Received: 2015.12.15

Accepted: 2016.02.01

Published: 2016.03.01

\begin{abstract}
When an earthquake occurs, the structure will enter into a nonlinear stage; therefore, new approaches based on nonlinear analysis are needed to flourish with the purpose of more realistic investigations on seismic behavior and destruction mechanism of structures. According to the modern philosophy, "Performance-based Earthquake Engineering” is formed in which simple nonlinear static analyses are mostly used in order to determine the structure's behavior in nonlinear stage. This method assumes that the structure response is only controlled by the main mode and the shape of this mode will remain the same, while it enters the nonlinear stage. Both of these assumptions are approximations, especially in high buildings, which have a long period. It seems that constant load pattern used in these methods cannot consider all of the effects properly. In this paper, an attempt was made to study the accuracy of these methods in comparison to nonlinear dynamic analysis, by considering various load patterns existing in FEMA, also load patterns proportional to higher modes in nonlinear static method, and employing an approximative method of MPA modal analysis, study the accuracy of these methods in comparison to nonlinear dynamic analysis. For this purpose, three steel frames of 4, 8, and 12-stories with steel shear wall have been studied.
\end{abstract}

Keywords: load patterns, steel shear wall, static nonlinear, dynamic nonlinear.

\section{INTRODUCTION}

With advancements in earthquake recognition, appearing growth in seismic improvement concepts and performance-based design, considering an accurate and realistic form of the structure behavior tends to gain more importance than before. It is essential to discuss various factors which depict the precise structure behavior, because it leads to a better prediction and prevention of damage. In fact, nowadays, only horrible and destructive disasters like earthquake in metropolises can feature the valuable aspects of the above mentioned issue. Moreover, demolition of buildings which are vulnerable to earthquakes and construction of alternative buildings requires enormous waste of time and cost that in some cases providing the necessary stuff is not even possible.
Among the methods which help the improvement and retrofitting of the buildings against earthquake is the steel shear wall method. In this present study the effects of higher modes in retrofitting of structures by means of shear wall was investigated.

In commencement of steel shear walls construction in the United States of America and Japan, vertical and horizontal stiffeners was used which restricted the buckling of sheet and improved the shear resistance of steel sheet. However, welding, which is necessary for junction of stiffeners to wall, was costly and time-consuming; as a result, plenty of studies and examinations were conducted on shear walls without stiffener in US and Japan. The main idea for the usage of steel plate shear walls without stiffeners is to profit from diagonal strain field that is present af- 
ter the buckling of steel sheet. This phenomenon is post-buckling in steel sheet, which is common in beam-plates. In this case the panel resists until the yielding of the steel sheet which will cause them to endure considerable forces.

The first studies on beam-plates were in 1980's at Alberta University, Canada by Coolak, Driver, Timler and et al. [1, 2, 3]. Following them, many other scientists, e.g. Bruneau and Bhagwagar [4], Berman and Bruneau [5], Elghali et al. [6, 7], Astaneh Asl [8, 9], and Sabouri Ghomi [10, $11]$ have examined numerous tests on the subject.

\section{MODELING OF STEEL SHEAR WALLS}

Steel shear wall systems without stiffener include steel plate panel, two boundary columns and horizontal beams at the bottom. It is required that each steel shear wall resists horizontal shear of stories and overturning anchor due to lateral loads. The shear wall, along with two columns, acts as a vertical cantilever beam-plate. Columns act as sheet beam flange, wall panels as web sheets and bottom beams as transverse stiffeners of web sheets. Investigations on panel behaviors in the case of no stiffener showed that there would be much more ductility and energy dissipation comparing to the case where stiffener exists; as a result there have been recent trends towards the matter in United States and Canada.

Theoretical studies on design and analysis of steel shear walls concluded in two ultimate behavioral models of the context. The first model is based on substitution of diagonal strips with doubler plate (strip model) which has been introduced by Thorburn (1983) in order to design steel shear walls. It is also accepted as an appendix to Canadian Steel Standard (CAN/CSA S16-01) and is shown in Figure 1 [12]. Moreover, this method is mentioned in seismic provisions for Structural Steel Buildings (AISC 2005) in chapter 17 [13]. The second model is based on the plastic yielding of the plate with surrounding frame (plastic yielding model) presented by Sabouri \& Roberts (1991) [10]. In this study the first model is employed to design steel shear walls.

The design procedure is that firstly for preliminary cross sections design of beam, column and web, similar shear wall is approximated by a vertical truss with tension braces. In fact, each steel plate is represented by an equivalent brace. After the structural analysis and calculation of

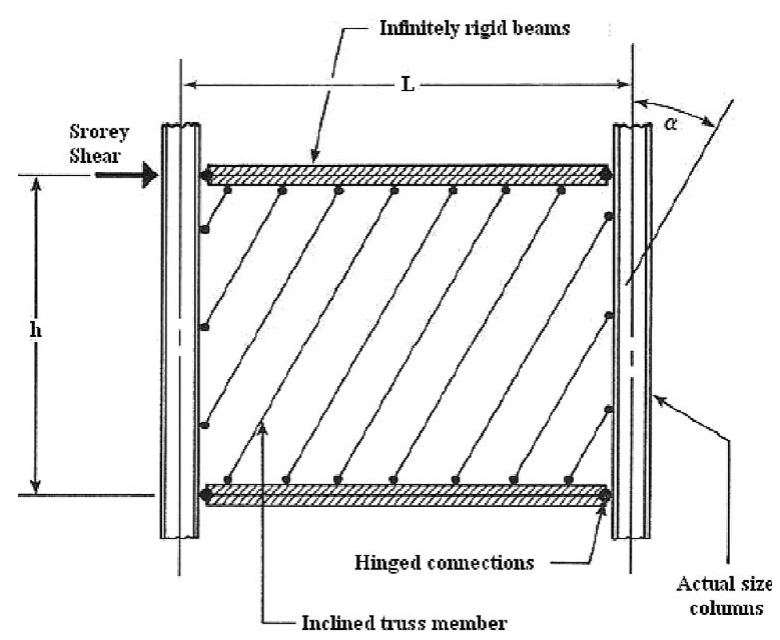

Fig. 1. Thorburn strip model (using truss elements) [1]

cross-sectional area of braces, based on the elastic stress energy formula (equation 1) for the assumed angle of the tension field, the steel plate thickness can be achieved. Then, by using stiffness of beam, column, and plate thickness, the angle of the tension field $(\alpha)$ is taken place in the sheet.

$$
\mathrm{t}=\frac{2 \mathrm{~A}_{\mathrm{b}} \Omega_{\mathrm{s}} \sin \theta}{\mathrm{L} \sin 2 \alpha}
$$

where: $\Omega_{\mathrm{s}}$ - system's over-strength factor, which is 1.2 for shear walls;

$\theta$ - the angle between brace and column. $L$ - distance between column centerlines. $\alpha$ - the angle of inclination of the tension field in the steel plate (angle of replaced diagonal strips with vertical direction) according to figure 1 which is obtainable from equation (2).

As in the current study, the steel panels do not have hardening (stiffener), though they possess high width-to-thickness ratio, and when lateral forces are prescribed, they behave as deep beam sheets. The tension field is formed in tensile diameter direction and considerable forces are imposed in this way, while in direction of compression diameter with critical plate-buckling little tensions take form. When force side changes, direction of tension field and forces transfer is inversed. The inclination angle of the tension field depends to the geometrical properties of building and cross sections of walls boundary members (beam and column). The Canadian Standard proposes the following equation for this angle calculation:

$$
\tan ^{4} \alpha=\frac{1+\mathrm{t}_{\mathrm{w}} \mathrm{L} / 2 \mathrm{~A}_{\mathrm{c}}}{1+\mathrm{t}_{\mathrm{w}} \mathrm{h}_{\mathrm{s}}\left(1 / \mathrm{A}_{\mathrm{b}}+\mathrm{h}_{\mathrm{s}}{ }^{3} / 360 \mathrm{I}_{\mathrm{c}} \mathrm{L}\right)}
$$


where: $L$ and $h_{s}$ are length and height of throat, $A_{b}, A_{c}, I_{c}$ are cross sections of beam, column and the moment of inertia of a column respectively, while $t_{w}$ is the thickness of the web.

After that, by using equation (3) sheet is transformed into some equivalent strips. Regarding the experimental results and recommendations of other researchers (Astaneh [8,9]) at least 10 members in the throat were used while creating diagonal strips. The cross section area of these members is in rectangular form and is equal to the distance between two strips; the thickness of the members is the same as the calculated thickness of the design.

$$
A_{s}=\frac{L \cos \alpha+h_{s} \sin \alpha}{n} \times t_{w}
$$

where: $L, h$ are width and height of wall throat.

In order to insure the quality of the side columns stiffness that will not endure any suffering from buckling while they are exposed to diametrical tension, the moment of inertia should be as follows:

$$
\mathrm{I}_{\mathrm{c}} \geq \frac{0.0030 \pi \mathrm{t} \cdot \mathrm{h}_{\mathrm{s}}{ }^{4}}{\mathrm{~L}}
$$

In this method, the Canadian Standard sets this commitment that besides the initial design, columns should be controlled with $B$ coefficient for forces from gravity loads combined with increased loads due to earthquake (equation (5)). The $B$ Coefficient is in fact the ratio of the expected resistance of wall to the design shear in the final case. Therefore, the increased resistance of the wall sheet can be observed in the final case and the columns are designed for that.

$$
\begin{gathered}
\mathrm{B}=\frac{\mathrm{V}_{\mathrm{e}}}{\mathrm{V}_{\mathrm{u}}} \\
\mathrm{V}_{\mathrm{e}}=0.5 \mathrm{R}_{\mathrm{y}} \mathrm{F}_{\mathrm{y}} \mathrm{t}_{\mathrm{w}} \mathrm{L}_{\mathrm{cf}} \sin 2 \alpha
\end{gathered}
$$

where: $R_{y}$ - is the ratio of average steel yielding tension to design yield tension, $F_{y}$ - is steel plate's design yield tension, $\mathrm{L}_{\mathrm{cf}}^{\mathrm{y}}-$ is the net distance between columns. $\alpha-$ is the inclination angle of the diametrical tension field in steel plate, $t_{w}$ - is the thickness of the web plate.

In this approach, axial forces in the column due to earthquake should be obtained from overturning anchor $\mathrm{BM}_{u}$ where $\mathrm{M}_{\mathrm{u}}$ is the anchor at column's end due to seismic loads $\mathrm{V}_{\mathrm{u}} \cdot \mathrm{BM}_{\mathrm{u}}$ anchor must be considered at least for two first stories. After that, the anchor in other stories is cal- culated from multiplication of overturning anchor of that storey to coefficient B. Moreover, bending anchors of columns which are due to tension field of the web plate must increase according to B coefficient then the design continues.

For studying and calculation of structures vibration modes, they can be modeled in CSI group software environments including Etabs2000, Sap2000, and Perform 3D. In the present research, the results obtained from nonlinear static analysis of three building frames under different lateral loading patterns are compared with the results of nonlinear dynamic analysis.

\section{REVIEW OF STU5DIED MODELS}

In purpose of simplicity, the studied models of the present study were considered as three building frames of 4, 8, and 12 symmetrical stories, five throats with 4 meter width along with average bending steel frame. The height of all stories is equal to 3.3 meters high. The structure roofs are considered to be built from joist and to be rigid. The aim of the base improvements and structures usages is educational matters. The gravity loading is computed according to Iranian loading standard [14]. In addition, base shear was taken into account corresponding to standard 2800 [15], then harm amount study for buildings has been made according to criteria mentioned in Fema356 [16] and techniques presented in reference book [17]. It was revealed that the under study buildings are not capable to respond to the prescribed loading and hence require improvements. As a result, for structural reform the steel shear wall is employed. For the purpose of designing steel shear wall, lateral loading due to earthquake must be calculated first. Appendix R from American standard has proposed $\mathrm{R}=11$ for bending frame dual system behavior coefficient with steel shear walls without stiffeners. In this case, by having R, earthquake can be calculated according to corresponding static method in Iranian 2800 standard.

Building plans which have been studied in this paper is presented in Figures 2a (4 storey building frame), 3a (8 storey building frame), 4a(12 storey building frame) besides the results of conducted analysis according to the following explanations.

The masonry assumptions are as follows: Steel St37, yield tension $\mathrm{F}_{\mathrm{y}}=2400 \mathrm{~kg} / \mathrm{cm}^{2}$, elastic stiffness $\mathrm{E}=2.1 \times 10^{6} \mathrm{~kg} / \mathrm{cm}^{2}$. The structural loading and nonlinear joints definition (for all beams 
and columns) and computation of change in target location are all according to criteria written in the Fema 356 and ATC 40 [18]. It worth mentioning that, the force-web strip members' location change curve is modeled by two line elasto-plastic model. The effects of hardening stress are also considered with a slope of $3 \%$ in recessive part. Modeling parameters and acceptance criteria of shear wall elements as an axial member in the traction is like an ordinary traction member (according to FEMA 356 and seismic AISC criteria) and has small compression resistance.

\section{THE PROCEDURE AND TECHNIQUES OF MODELS ANALYSIS}

\section{Nonlinear dynamic analyzing method and modal analysis}

In order to perform nonlinear dynamic analysis on the frames, also modal increased load analysis of a system with one degree of freedom seven pairs of registered acceleration mapping consist of: El centro, Kobe, Naghan, ChiChi, San Fernando, Northridge, Bam are used; all of these mappings are held on type II (according to Iranian standard 2800) as time history of earth drastic movement. Regarding Iranian Standard 2800, all of these acceleration mappings should be tantamount. In this study, the average spectrum from seven pair of acceleration mapping is coordinated with design spectrum of Standard 2800 for soil type II. After that, nonlinear dynamic analysis of principal structure is held by means of selected acceleration mappings.

Following that, by operating modal analysis the numerical amount of $\omega_{n}$ and $\phi_{n}$ is calculated for each mode. Then, Pushover analysis for each mode is done with load distribution pattern of $S_{n}^{*}=m \phi_{n}$, and the base shear-roof displacement curve $\left(V_{b}-V_{m}\right)$ is idealized by a bilinear procedures. After all, the fundamental curve is transferred by $\left(F_{s n} / L_{n}\right)-D_{n}$ format for each mode [19, 20].

System nonlinear dynamic analysis SDOF of $n$th mode is operated for each of the acceleration mappings in order to calculate the maximum deformation $\left(D_{n}\right)$ with force - displacement relation $\left(\left(F_{s n} / L_{n}\right)-D_{n}\right)$. For each mode the average of responses are calculated and it is followed by the calculation of the maximum roof displacement or target displacement for each mode. Until reaching the target displacement the main structure (MDOF) will be assumed as push. Response quantity in target displacement in each mode is calculated and overall response for adequate modes are combined by statistical methods such as SRSS.

In this paper, the responses resulted from MPA method (Modal Pushover Analysis) and conventional Pushover method with FEMA load distribution pattern is compared with responses from nonlinear dynamic technique. Response quantities include maximum storey displacement, relative storey displacement, and base shear. In order to conduct system nonlinear dynamic analysis MDOF, SAP2000 v. 14 is employed; also for nonlinear static analysis Etabs2000 v. 9.7 software is used which are approved by Berkley university researchers.

\section{Pushover analysis according to FEMA 273}

In this study, in order to avoid errors from different approximative methods of target displacement determination into calculations, roof displacement resulted from MPA method is used for FEMA load distribution patterns. Thereby, for structure pushover analysis, with relative load pattern modes, uniform and SRSS is operated.

Three main FEMA load patterns which were studied in this research and the pushover analysis is held upon them can be summarized as follows:

Uniform distribution: in this pattern, the prescribed forces into each storey is relative to the mass and is obtained from the following equation:

$$
S_{j}^{*}=\frac{m_{j}}{\sum_{i=1}^{N} m_{i}}
$$

Equivalent lateral force (ELF): which is usually used when more than 75 percent of overall mass contributes in the base mode on the under study direction.

$$
S_{j}^{*}=\frac{m_{j} h_{j}{ }^{k}}{\sum_{i=1}^{N} m_{i} h_{i}^{k}}
$$

where: $i$ is the number of storey and $i=1,2, \ldots, N$.

In the above equation $k=1$ for the base period $T_{1} \leq 0.5, k=2$ for $T_{1} \geq 2.5$ seconds and varies linearly between these two amounts.

SRSS pattern (distribution) - lateral load in this method is dependent on Inertia forces deduced from elastic spectrum analysis. In this anal- 
ysis the modes contributions must be to the extent that 90 percent of the mode mass contribution to be taken into account. This analysis takes place by appropriate earthquake spectrum.

$$
\tilde{\mathrm{f}}_{\mathrm{j}}=\frac{\mathrm{f}_{\mathrm{j}}}{\sum_{\mathrm{i}=1}^{\mathrm{N}} \mathrm{f}_{\mathrm{i}}}
$$

According to FEMA guidelines, other proper load patterns which have previously been examined and controlled, can replace the above ternate patterns.

\section{EXAMINED OUTCOME PARAMETERS FROM ANALYSIS RESULTS}

Following the conducted analysis, by prescribing the existing FEMA patterns and load mode patterns applied in MPA method on selected modes, a comparison of these methods' accuracy and ability in facing structural responses with results from the precise method of nonlinear dynamic analysis is done.

As it was mentioned before, the response parameters which have been derived from analysis and have been compared to each other are as follows:

- the maximum floor displacement in percentage from building's height,

$$
\left(\frac{\text { FloorDisplacement }}{\text { HeightFrame }} \times 100\right)
$$

- relative floor displacement in percent (Drift Ratio),

$$
\left(\frac{\text { FloorDrift }}{\text { StoryHeight }} \times 100\right)
$$

- base shear from the above mentioned parameters, the second parameter has the most importance in estimation of building destruction.

Next in this section, significant points in conducted analysis and a summary of principal methods are presented together with the manipulated method in this study.

\section{Idealization of bilinear pushover curve}

Various methods can be applied for making nonlinear systems as bilinear ones. In this paper, it is intended to equalize the structure capacity curve, thus, MATLAB programming environment is used in order to make the structure capacity curve bilinear, according to FEMA 356. Therefore, the equivalent pushover curve of a system with one degree of freedom is idealized in a way that the area beneath the bilinear curve is equal to the area under the pushover curve. Because the maximum amount of roof drift is not given at the beginning, choosing the ultimate point of pushover curve and the surface under it can raise some doubts. Hence, in order to determine the area under the pushover curve and its bilinear idealization an iterating method is employed. On the first step, a point is assumed as the selected displacement target on the pushover curve, and then the area under the curve is calculated right from the assumed point. According to this calculated area, the pushover curve is idealized in a bilinear form. By means of the achieved bilinear curve, the nonlinear dynamic analysis is performed and the peak displacement of the ideal bilinear system can be obtained. This peak displacement is compared with the initial assumed point. If these two points coincide, the target is reached, else the peak displacement due from nonlinear dynamic analysis is substituted with the initial presumed point and the process is once again repeated until the initial assumed point and the corresponding point of peak displacement for a system with one degree of freedom would converge equally with each other.

\section{Determination of the peak displacement for nonlinear systems with one degree of freedom}

In conventional Pushover methods, for determining the peak displacement of equivalent system with one degree of freedom and estimation of target displacement in different orders, various methods can be used. These methods can be categorized in three groups:

- FEMA 356 method (displacement coefficient methods), in this method the response of a nonlinear system with one degree of freedom is estimated from the elastic response of system with one degree of freedom and by means of adjustment factors.

- Capacity spectrum method (ATC-40), in this method the simplified elastic response spectrum (demand spectrum) is used in acceleration-displacement (ADRS) format. In fact, instead of using inelastic demand spectrum the elastic spectrum equivalent with high damping is applied. Besides, the nonlinear system with one degree of freedom is equalized with a linear system with low stiffness and high damping ratio. 
- $\mathrm{N} 2$ method, in this method in order to estimate the maximum displacement of the equivalent system with one degree of freedom, inelastic spectrum with different formation ratio $(\mu)$ is directly used.

\section{Averaging of target displacement}

The accuracy of the MPA method is totally dependent to severity of earth movements. The results of this method can be trusted only if the MPA procedure is performed for some earthquakes and from the achieved results are averaged. This process requires massive and time consuming calculations.

In this study and during the performed procedures, seven pairs of accelerating mappings are used for nonlinear dynamic analysis but the records are compared according to 2800 standard criteria whose responses must be averaged based on FEMA 356. The common method in averaging is arithmetical method in which the sum of responses is divided by their number and the contribution of each response in the average amount is supposed equal. This method is valid for estimating linear methods but because of complicated essence of responses in nonlinear dynamic analysis, this method does not seem to be proper. Therefore, there is another method which is exponential averaging. Converting the sophisticated parameters to logarithmic coordinates will cause the changes to accede to linear state which is usual in seismic engineering.

In this paper, the arithmetical averaging method is employed; however, for maximum displacement of equivalent system with one degree of freedom under nonlinear dynamic analysis regarding the nonlinear nature of the responses, exponential averaging is used.

For utilization of exponential averaging method, average $D_{i}$ is obtained from the following equation:

$$
\hat{\mathrm{D}}(\mathrm{n})=\exp \left[\frac{\sum_{\mathrm{i}=1}^{\mathrm{n}} \operatorname{Ln}\left(\mathrm{D}_{\mathrm{i}}\right)}{\mathrm{n}}\right]
$$

\section{RESULTS PRESENTATION AND EVALUATION OF PERFORMED ANALYSIS (FOR UNDER STUDY BUILDING FRAMES)}

\section{Analyzing 4-storey frame with steel shear wall}

For the analyzed 4-sorey structure illustrated in Figure 2a, a different analysis of nonlinear static and dynamic, which was explained in the previous sections, were performed. The results from nonlinear dynamic analysis of 4-storey frame are achieved according to selected acceleration mapping and pursuant to the process that have been described previously. The amounts of relative displacement and maximum storey displacement in nonlinear dynamic analysis of a 4-storey building are depicted in Figures $2 \mathrm{~b}$ and 2c respectively.

Moreover, a modal analysis is the first implemented for the structure; subsequently, in accordance with each of the first three modes, the pushover analysis with load pattern proportion to each mode is performed. In Figures 2d and 2g, responses of structure modal analysis, vibration mode of structure, bilinear idealized capacity curve (base shear according to roof displacement), base building shear, and effective base shear is shown. In addition, considering the implemented analysis, respectively in Figures $2 \mathrm{~h}$ and $2 \mathrm{i}$ the results of relative displacements and maximum storey displacement for different vibration modes are demonstrated and compared with the results of nonlinear dynamic analysis.

Following the performed nonlinear analysis on 4-storey structure frame, pushover analysis study according to FEMA guideline is carried out. In Figure $2 \mathrm{j}$, the results from structure pushover analysis and the shape of structure lateral load pattern is shown based on the three methods mentioned in this section. For these analysis and lateral load patterns, the idealized bilinear diagram of capacity curve (base shear according to roof displacement) can be achieved which have been considered in the conclusion section. In the following, in Figures $2 \mathrm{k}$ and 21 the final results of

Table 1. Amounts of building base shear in 4-storey frame by means of MPA estimations (in 3 modes), FEMA, and estimation errors

\begin{tabular}{|c|c|c|c|c|c|c|c|c|}
\hline \multicolumn{5}{|c|}{ Base shear [ton] } & \multicolumn{4}{|c|}{ Error [\%] } \\
\hline \multicolumn{3}{|c|}{ Fema } & \multirow{2}{*}{$\begin{array}{c}\text { MPA } \\
\text { (3 mode) }\end{array}$} & \multirow{2}{*}{$\begin{array}{l}\text { RHA } \\
\text { (Avg) }\end{array}$} & \multicolumn{3}{|c|}{ Fema } & \multirow{2}{*}{ MPA } \\
\hline Uniform & ELF & SRSS & & & Uniform & ELF & SRSS & \\
\hline 135 & 111 & 108 & 120 & 105 & 28 & 6 & 3 & 13 \\
\hline
\end{tabular}




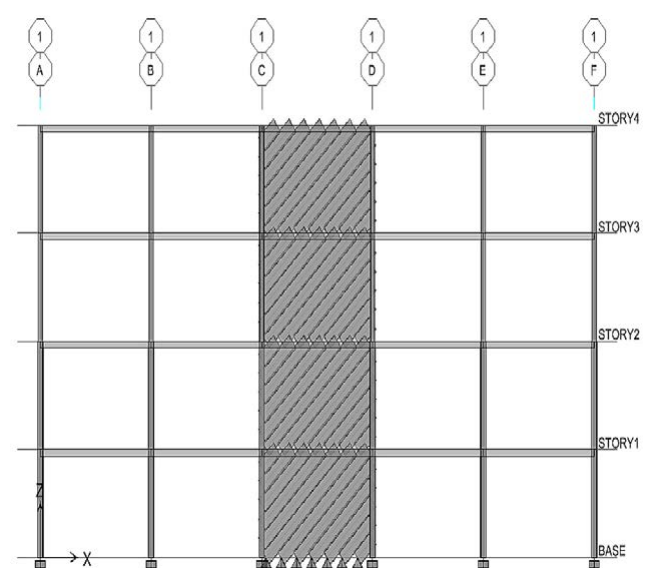

Fig. 2a. Frame under study of 4-storey building frame

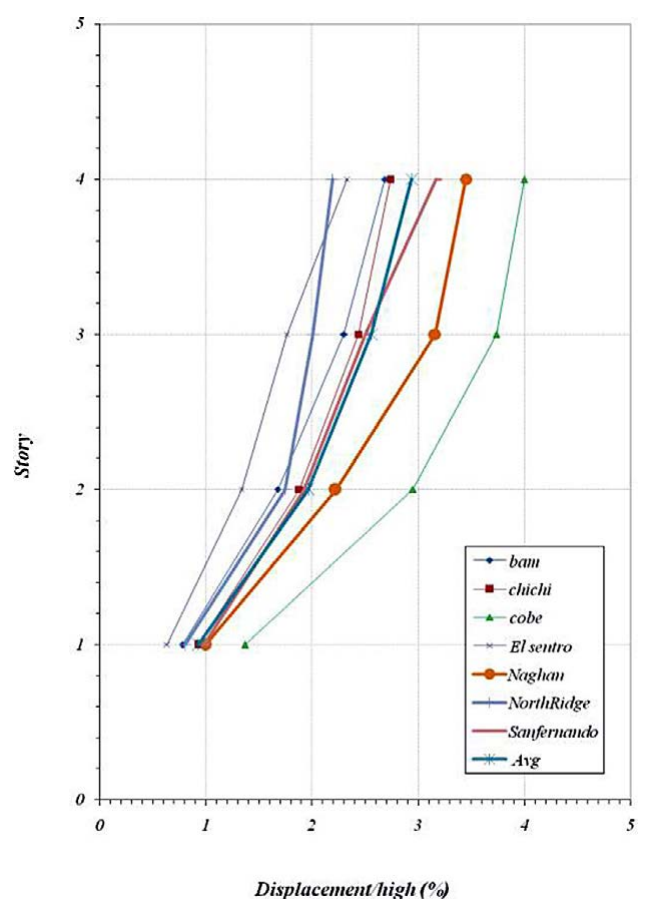

Fig. 2c. Maximum storey displacement in nonlinear dynamic analysis

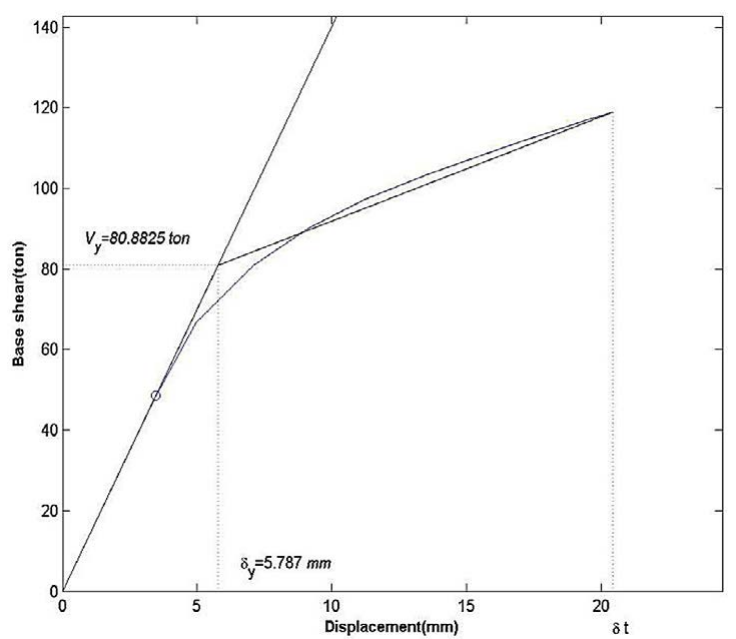

Fig. 2e. Pushover curve for first structure vibration mode shape

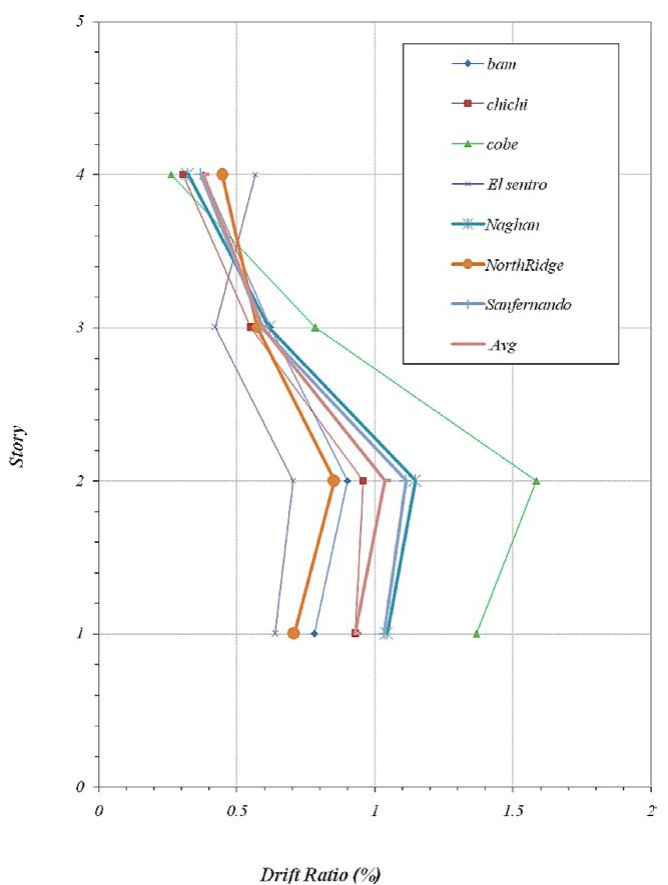

Fig. 2b. Relative displacement in nonlinear dynamic analysis

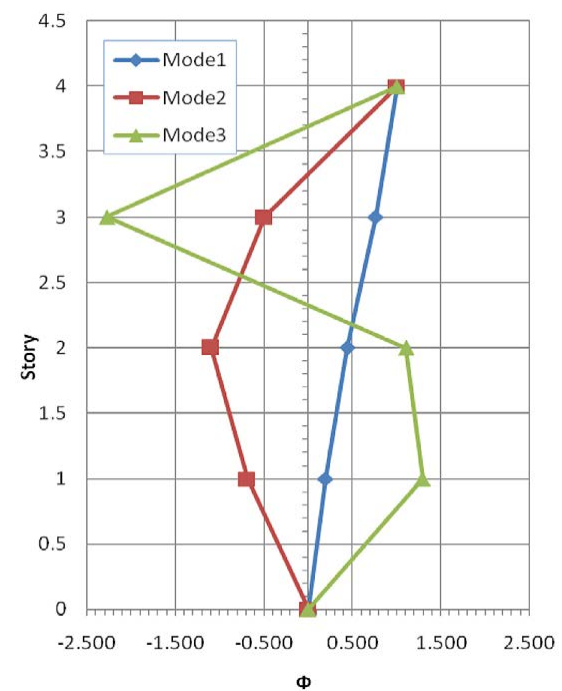

Fig. 2d. Structure mode shape in three first modes

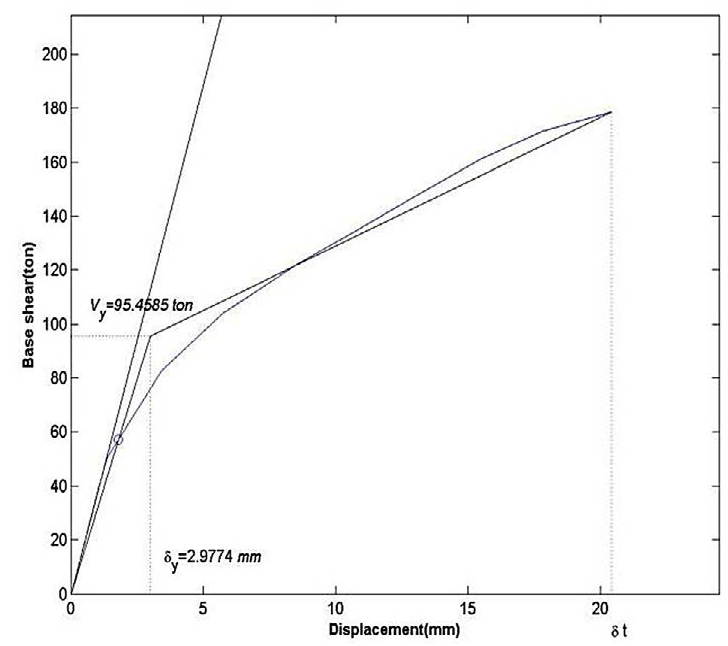

Fig. 2f. Pushover curve for second mode 


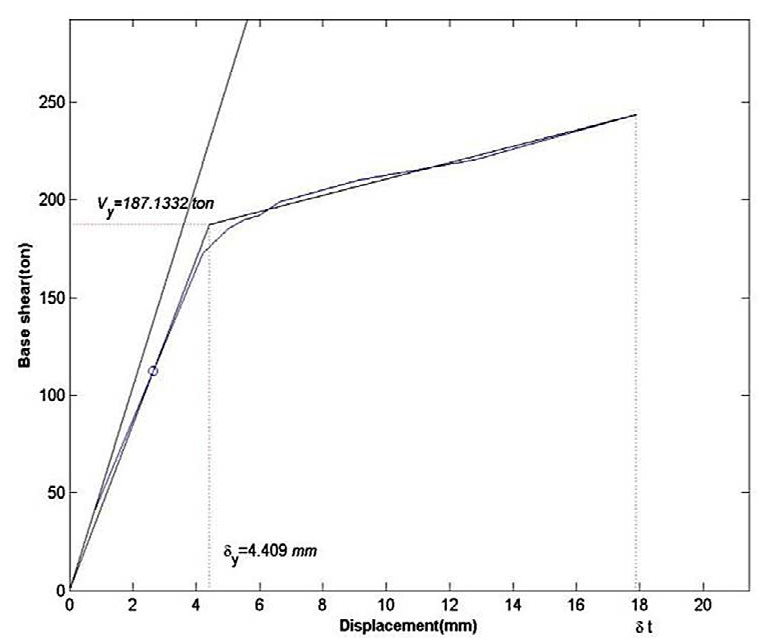

Fig. 2g. Pushover curve for third mode

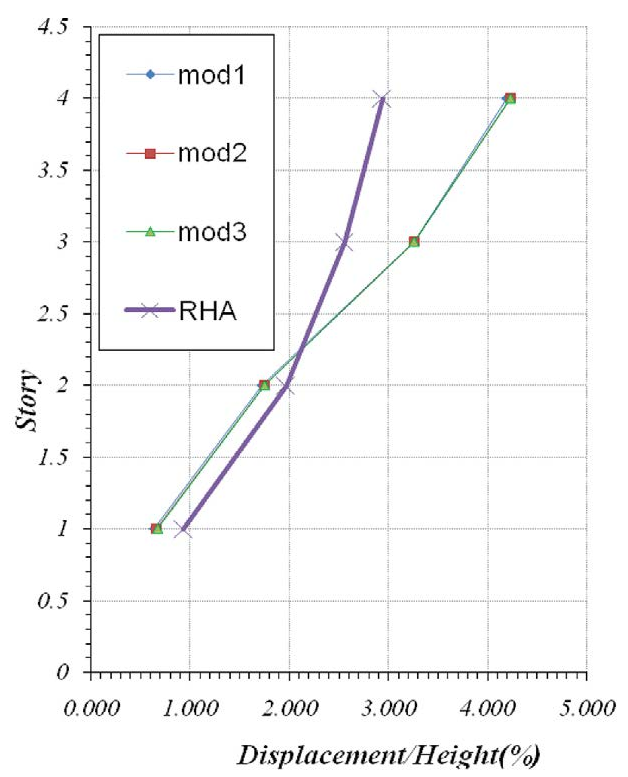

Fig. 2i. Determination of maximum storey displacement from MPA estimations

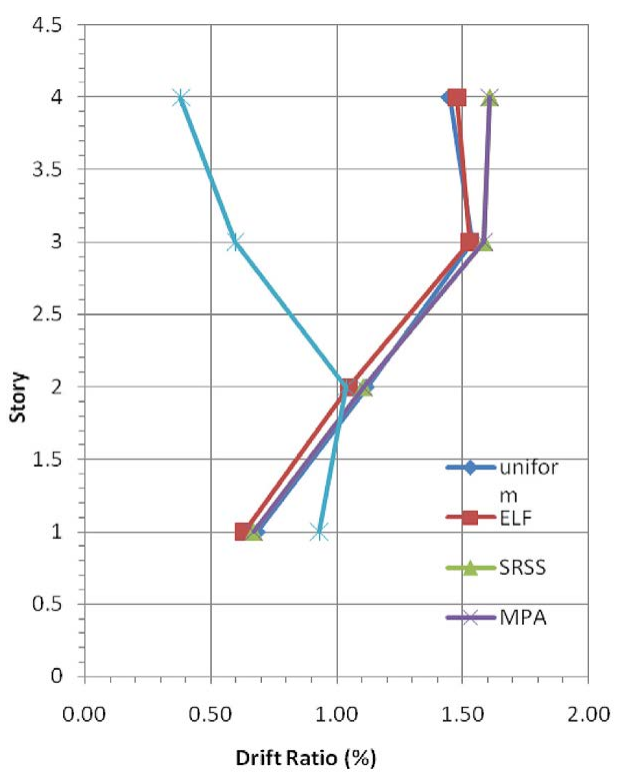

Fig. 2k. relative storey displacement from MPA and FEMA estimations

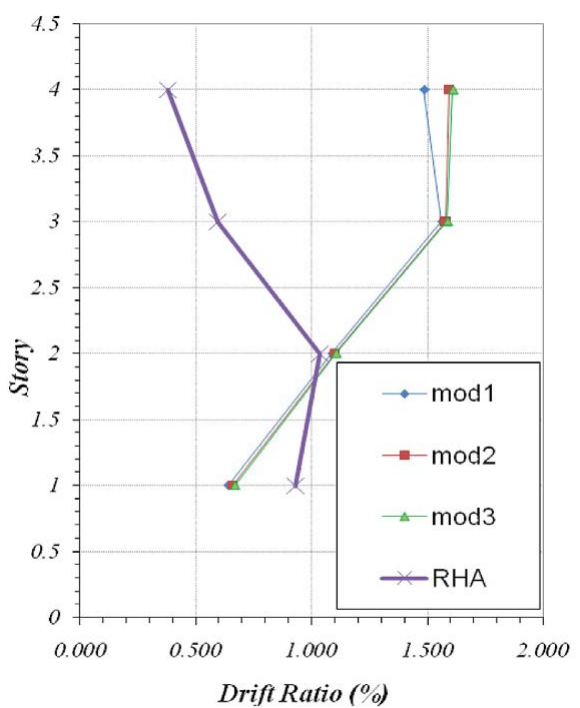

Fig. 2h. determination of relative storey displacement from MPA estimations

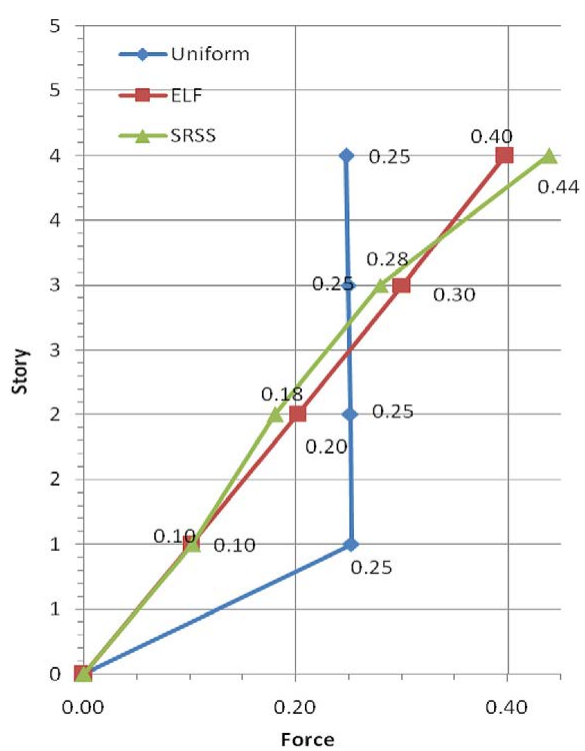

Fig. 2j. FEMA load distribution patterns scheme

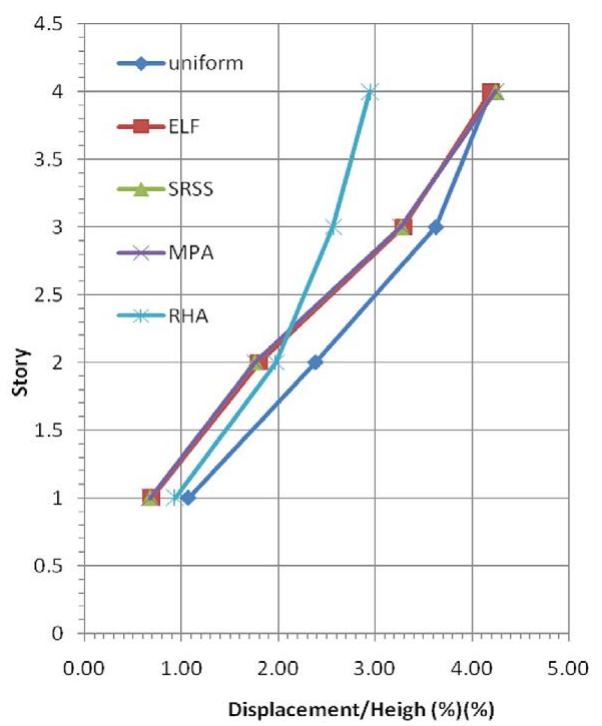

Fig. 2l. maximum storey displacement from MPA and FEMA estimations

Fig. 2. Analysis results for 4-storey structure 
relative storey displacement and maximum displacements by different methods are shown.

Table 1 summarizes the result comparison of base shear structure of 4-storey frame under various analysis.

\section{Results from 8-storey frame analysis with steel shear wall}

For the 8-storey frame pictured in Figure 3a, various nonlinear static and dynamic analyses likewise sections 4 and 5 have been performed. The results achieved from nonlinear dynamic analysis on 8-storey frame according to selected acceleration mappings and the mentioned procedure, the relative displacement and maximum storey displacement diagrams in nonlinear dynamic analysis are depicted in Figures 3b and 3c.

In other stages of the analyses, for the first structure the modal analysis is conducted; then based on each three first modes, the pushover analysis with load pattern proportionate to each mode is implemented.

Based on the results from structure mode shape in three first modes in Figure 3d, the pushover load curve (capacity or base shear curve in contrary to roof displacement) are drawn in Figures 3e and $3 \mathrm{~g}$. In these figures the bilinear idealized capacity curves of the structure (base shear according to roof displacement and effective base shear) can be observed. In Figures $3 \mathrm{~h}$ and 3i, the results from relative displacement and the maximum story displacement of MPA estimation in comparison with nonlinear dynamic method are presented. Moreover, for the performed nonlinear analysis of the 8-storey structural frame (as middle order frames), the pushover analysis is done according to FEMA guideline and load patterns. Figure $3 \mathrm{j}$ shows the structure lateral load pattern according to the three methods denoted before. For the accomplished pushover analysis with the recommended lateral load patterns, the bilinear idealized capacity curve (base shear according to roof displacement) is achieved. In Figures $3 \mathrm{k}$ and 31 the final relative story displacement and the maximum displacements can be observed based on different meth- ods. In Table 2, the result of comparison between the structure base shear under different analysis method for 8-storey frame is shown.

\section{Results from 12-storey frame analysis with steel shear wall}

For the 12-storey frame structure shown in Figure 4a, different static and dynamic nonlinear analyses have been performed. The results from nonlinear dynamic analysis for this frame according to selected acceleration mappings and the previously stated procedure are drawn in a form of relative displacement and maximum storey displacement diagrams which are depicted in Figures 4b and 4c.

Following the analyses for this frame, firstly the modal analysis is performed and then according to each three first mode, the pushover analysis with proportional loading pattern with each mode is done. In Figures $4 \mathrm{~d}$ to $4 \mathrm{~g}$, the results of structure modal analysis, vibration mode shape of the structure, the idealized bilinear capacity curve diagram (base shear according to roof displacement), and the amounts of building base shear, structure effective base shear, target displacement, and corresponding yielding shear displacement are presented. In addition, regarding the analyses, Figures $4 \mathrm{~h}$ and $4 \mathrm{i}$ respectively show the relative displacement and maximum storey displacement for different vibration modes, in comparison with the results from nonlinear dynamic analysis. Finally, the nonlinear pushover analysis according to FEMA guideline is performed on the structural 12-storey frame according to the explanations in previous sections. In Figure $4 \mathrm{j}$, the structure lateral load based on the three methods described in this section can be observed. For these analyses and also lateral load patterns, the idealized bilinear capacity curve (base shear according to roof displacement) is calculated. The results of structure pushover analysis are considered in conclusion section. Moreover, in figures $4 \mathrm{k}$ and $4 \mathrm{l}$, the final results of relative storey displacement and maximum displacements from various methods are shown. In Table 3, comparison results be-

Table 2. Amounts of building base shear in 8-storey frame by means of MPA estimations (in 3 modes), FEMA, and estimation errors

\begin{tabular}{|c|c|c|c|c|c|c|c|c|}
\hline \multicolumn{5}{|c|}{ Base shear [ton] } & \multicolumn{4}{|c|}{ Error [\%] } \\
\hline \multicolumn{3}{|c|}{ Fema } & \multirow{2}{*}{$\begin{array}{c}\text { MPA } \\
\text { (3 mode) }\end{array}$} & \multirow{2}{*}{$\begin{array}{l}\text { RHA } \\
(\text { Avg) }\end{array}$} & \multicolumn{3}{|c|}{ Fema } & \multirow{2}{*}{ MPA } \\
\hline Uniform & ELF & SRSS & & & Uniform & ELF & SRSS & \\
\hline 201 & 157 & 156 & 191 & 123 & 62 & 27 & 26 & 55 \\
\hline
\end{tabular}




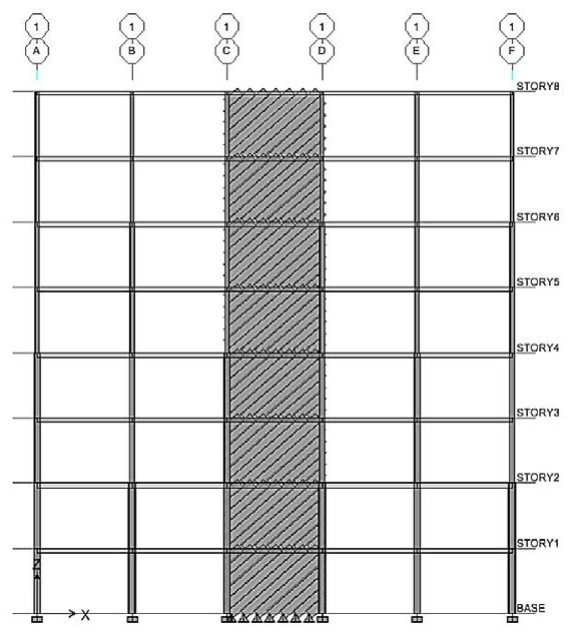

Fig. 3a. Frame under study of 8-storey building frame

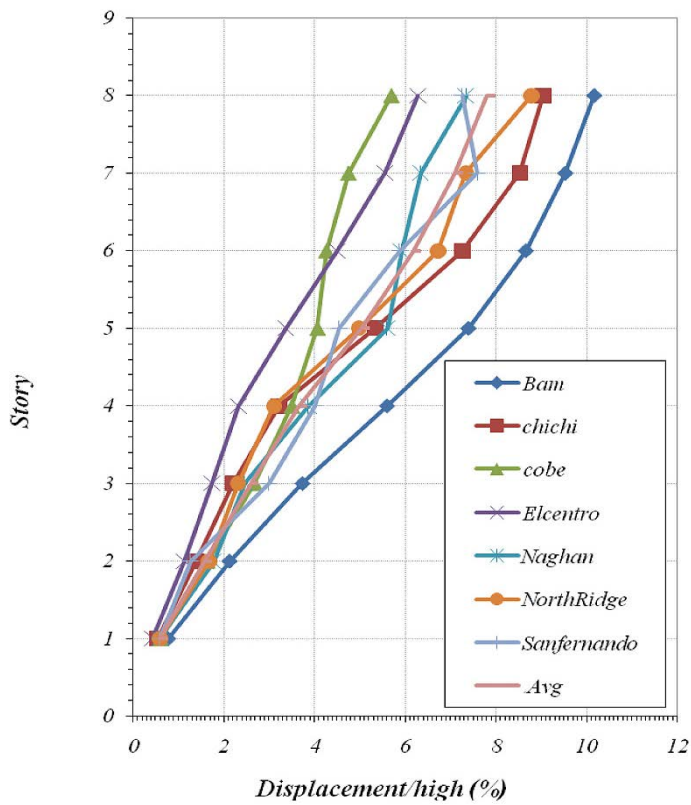

Fig. 3c. Maximum storey displacement in nonlinear dynamic analysis

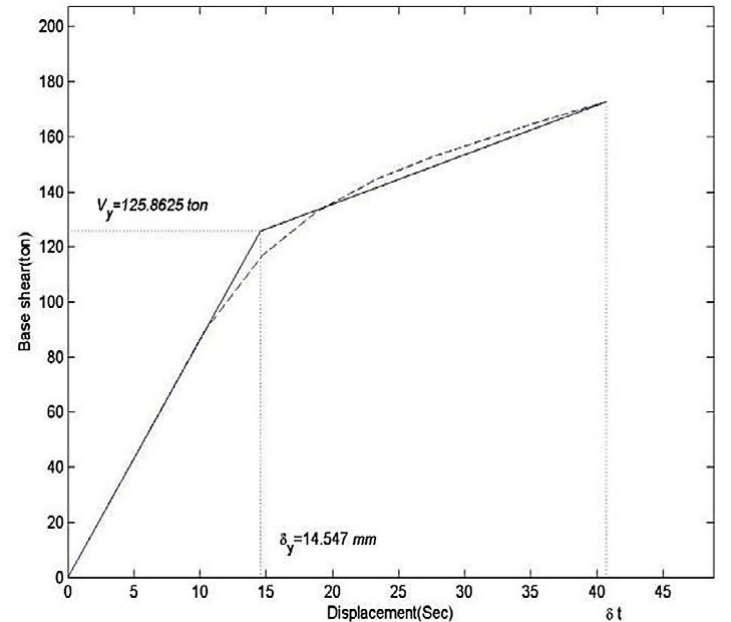

Fig. 3e. Pushover curve for first structure vibration mode shape

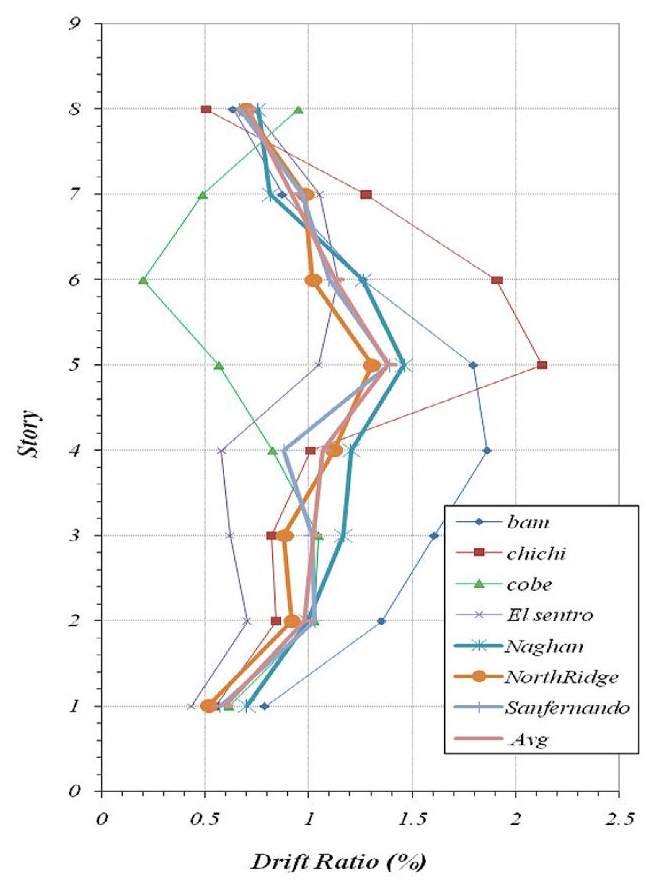

Fig. 3b. Relative displacement in nonlinear dynamic analysis

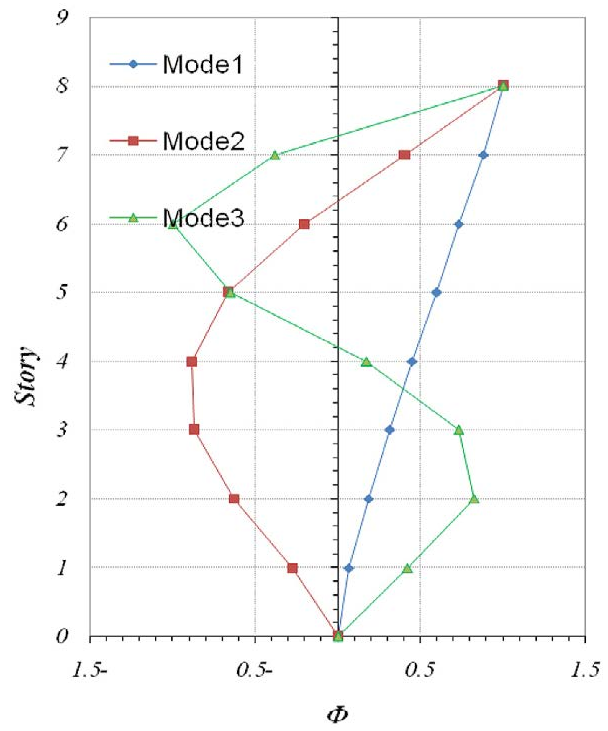

Fig. 3d. Structure mode shape in three first modes

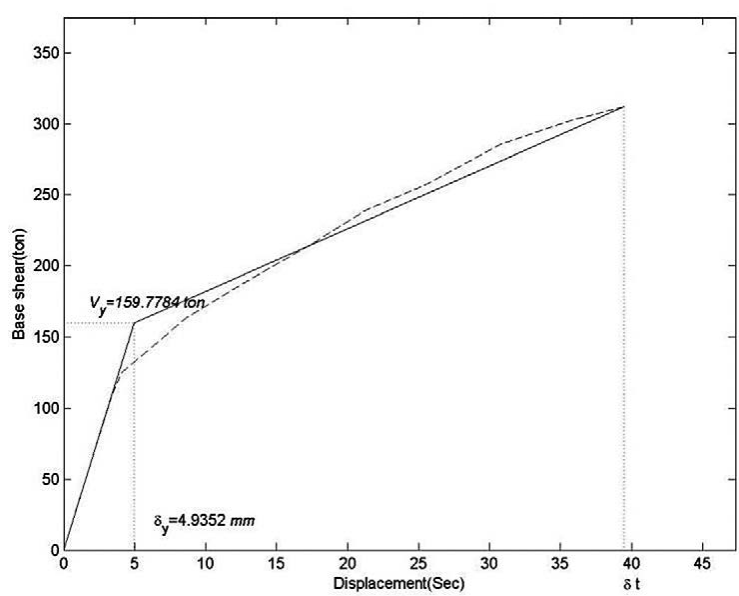

Fig. 3f. Pushover curve for second mode 


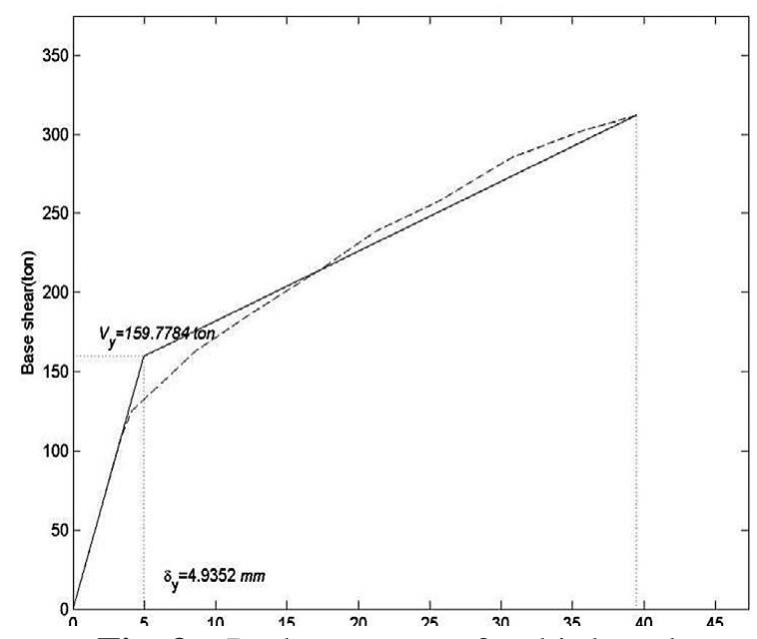

Fig. 3g. Pushover curve for third mode

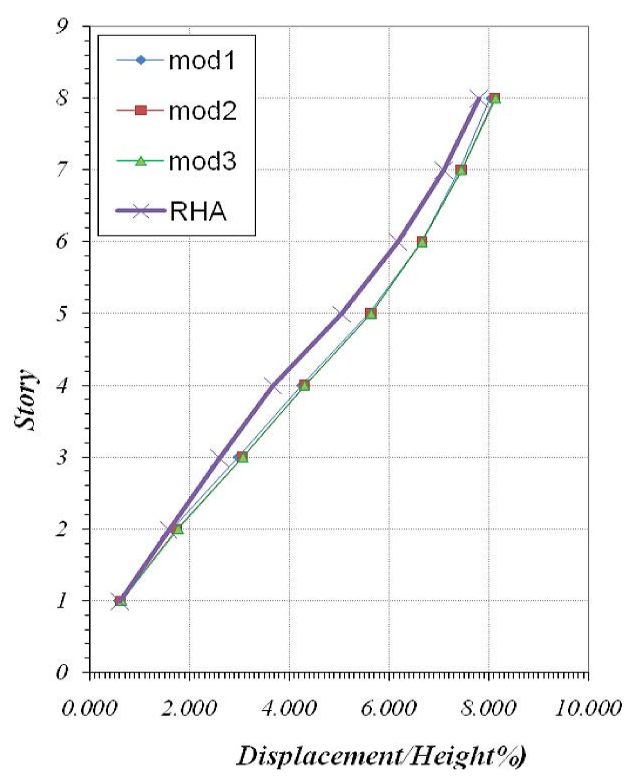

Fig. 3i. Determination of maximum storey displacement from MPA estimations

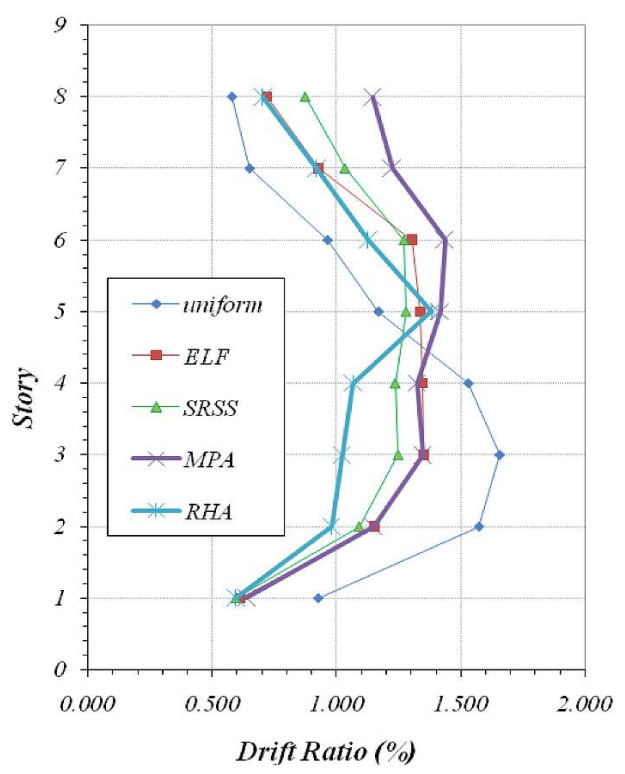

Fig. 3k. relative storey displacement from MPA and FEMA estimations

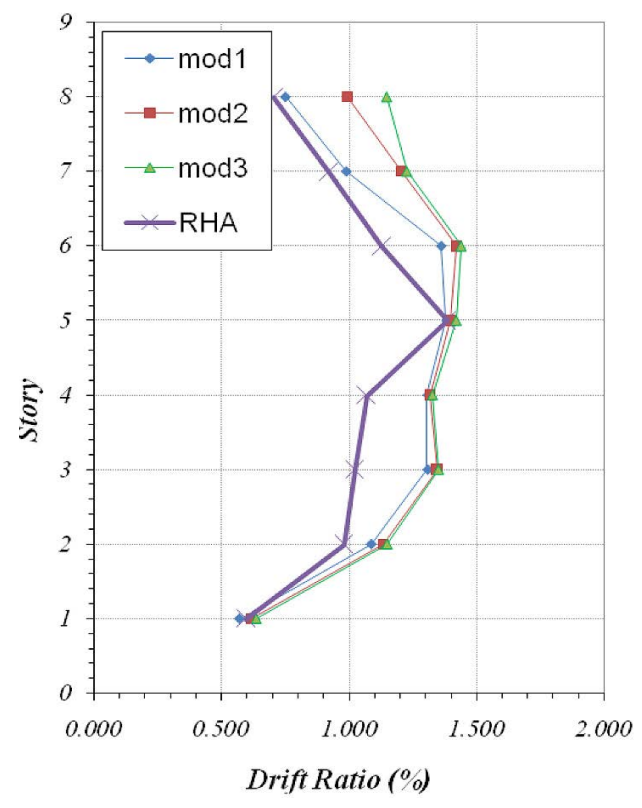

Fig. 3h. Determination of relative storey displacement from MPA estimations

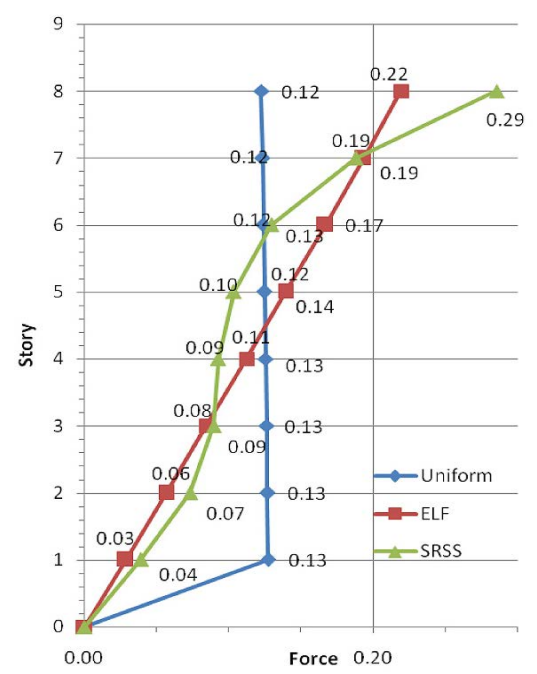

Fig. 3j. FEMA load distribution patterns scheme

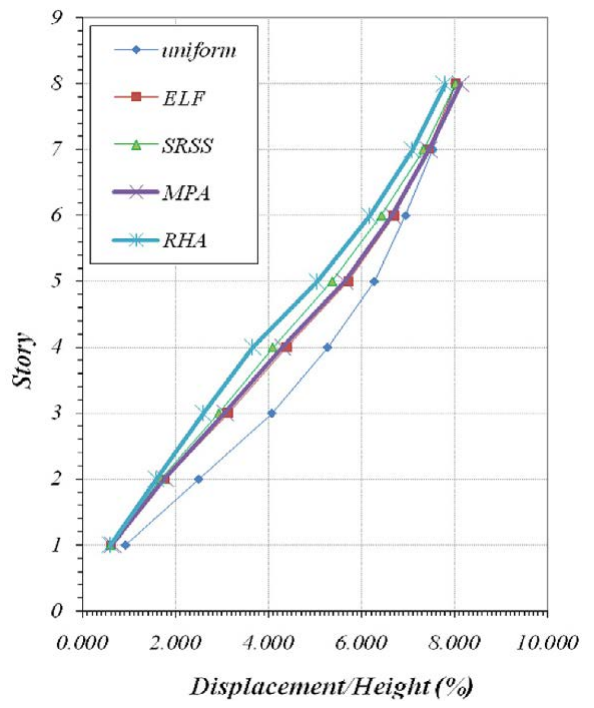

Fig. 3l. Maximum storey displacement from MPA and FEMA estimations

Fig. 3. Analysis results for 8-storey structure 


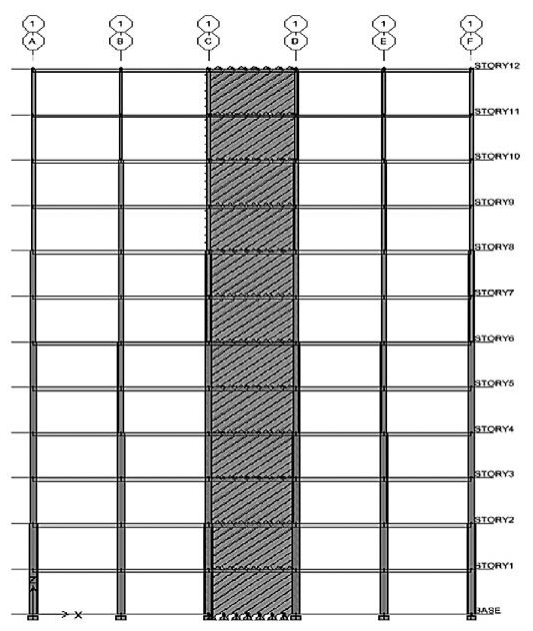

Fig. 4a. Frame under study of 12-storey building

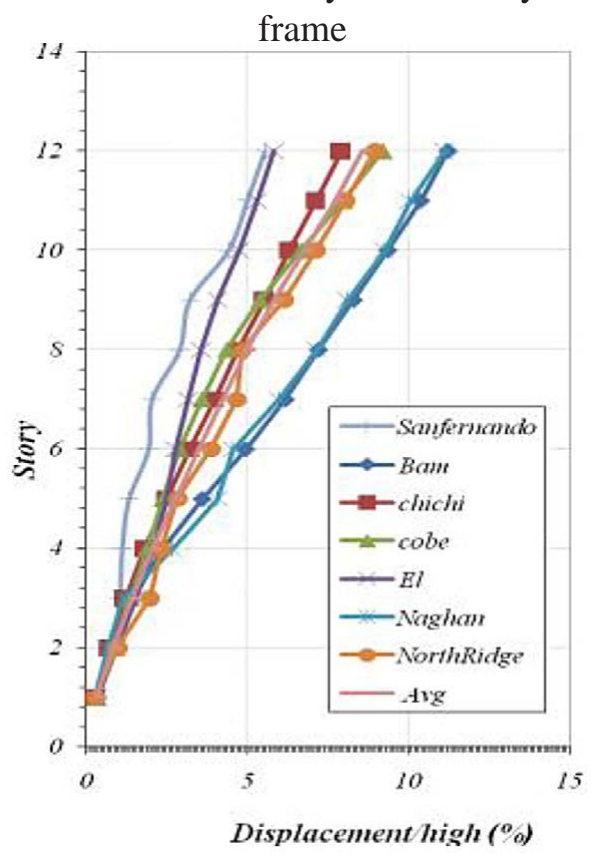

Fig. 4c. Maximum storey displacement in nonlinear dynamic analysis

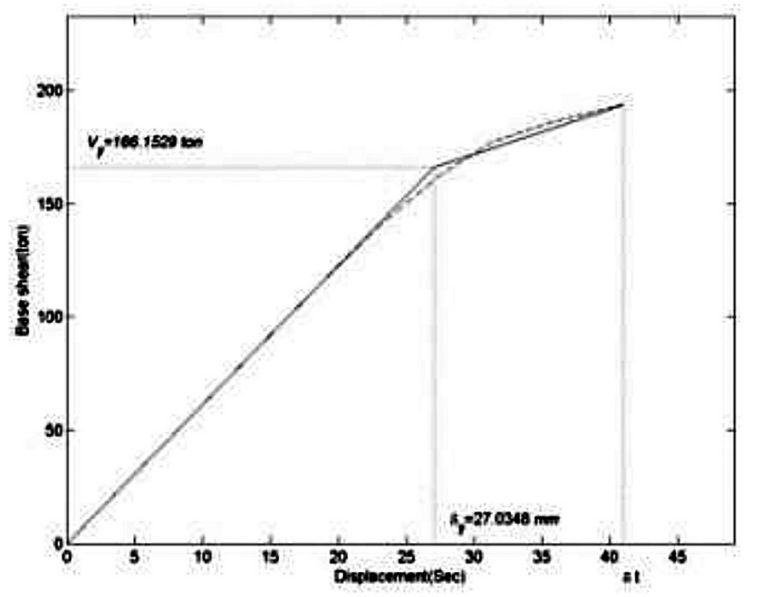

Fig. 4e. Pushover curve for first structure vibration mode shape

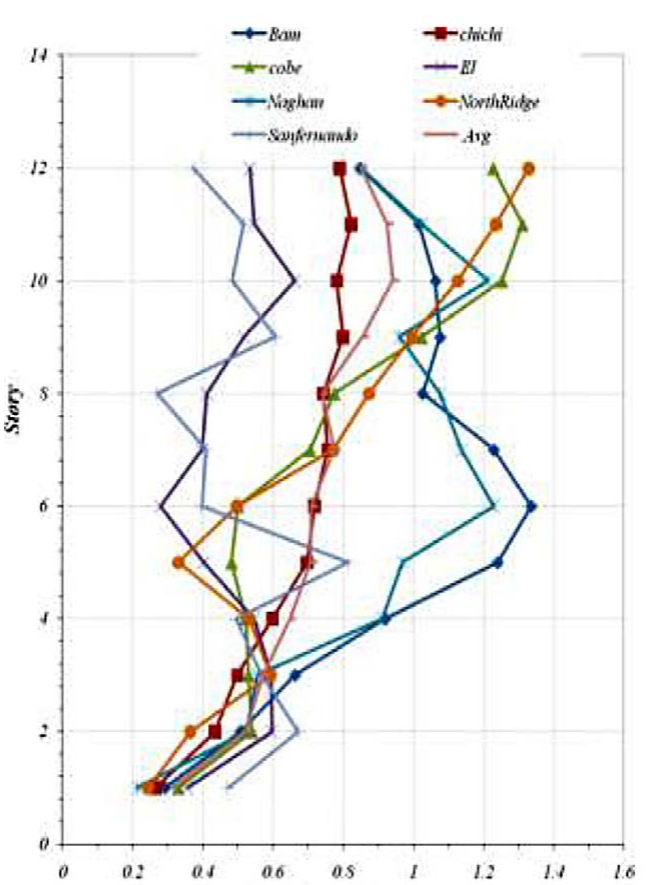

Fig. 4b. Relative displacement in nonlinear dynamic analysis

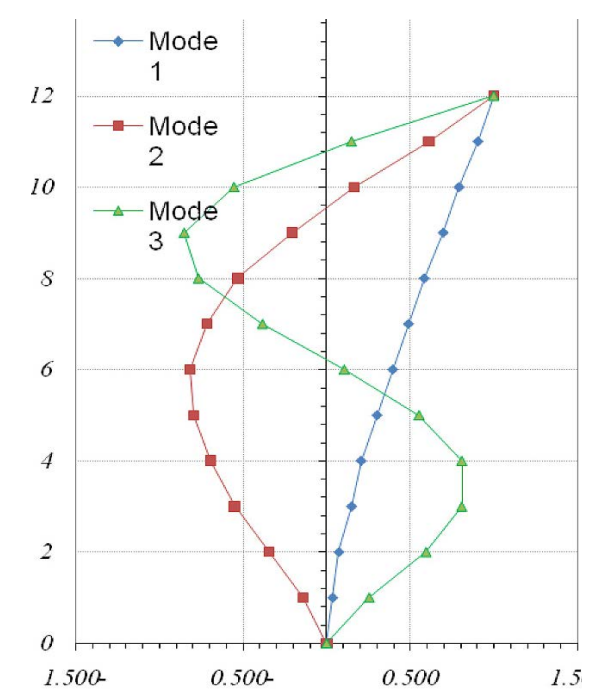

Fig. 4d. Structure mode shape in three first modes

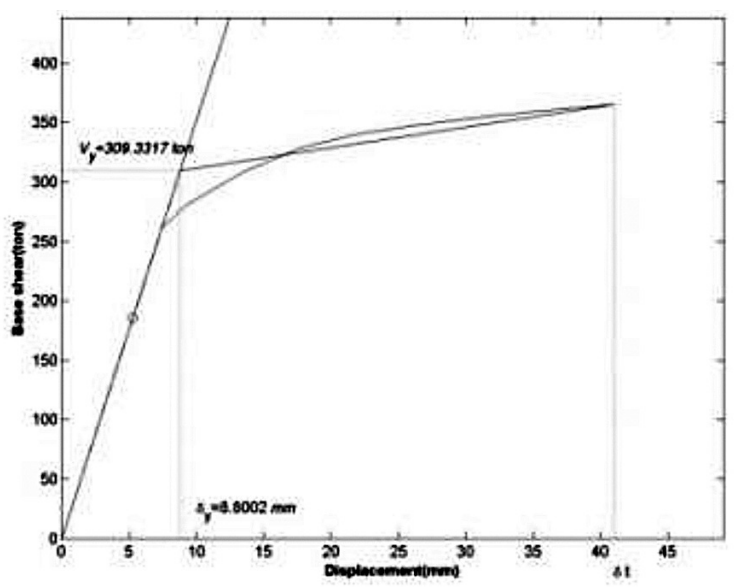

Fig. 4f. Pushover curve for second mode 


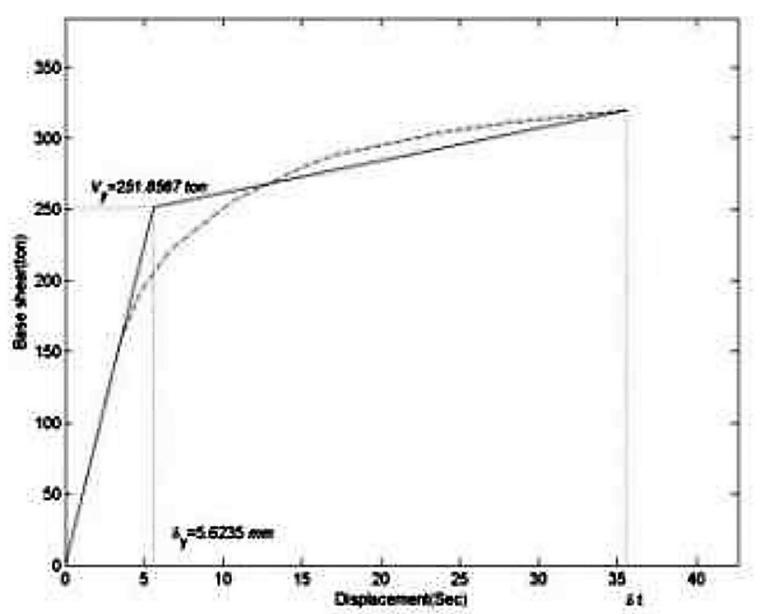

Fig. 4g. Pushover curve for third mode

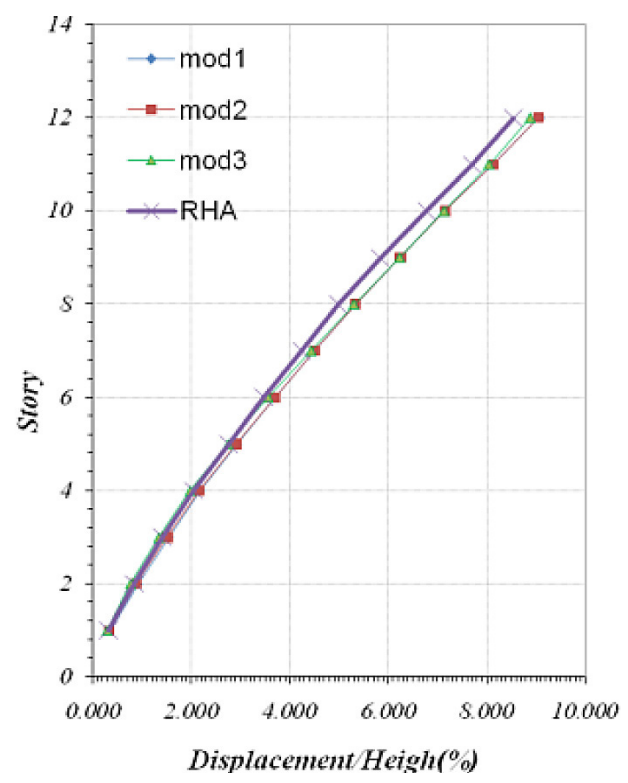

Fig. 4i. Determination of maximum storey displacement from MPA estimations

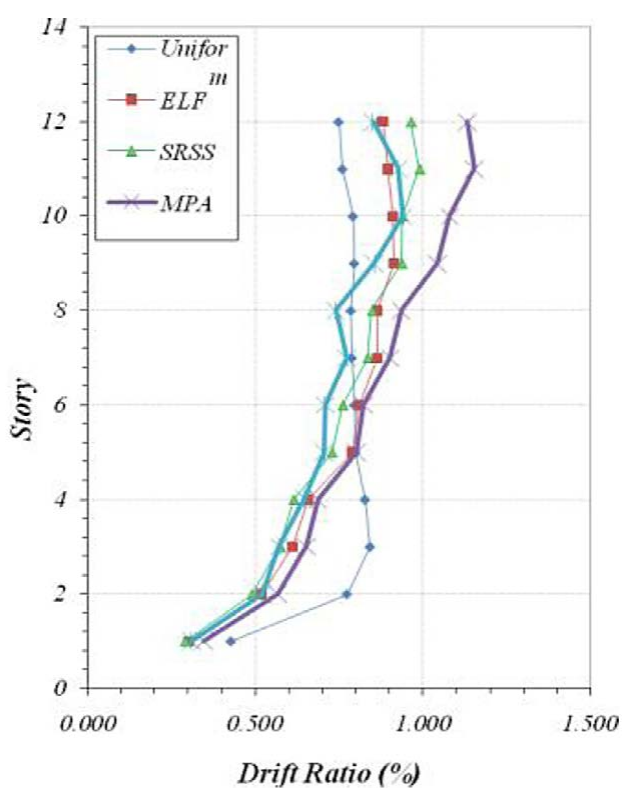

Fig. 4k. relative storey displacement from MPA and FEMA estimations

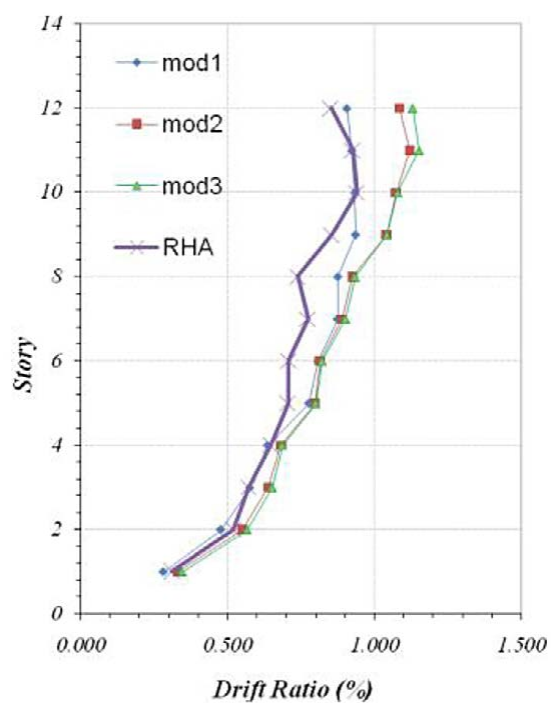

Fig. 4h. Determination of relative storey displacement from MPA estimations

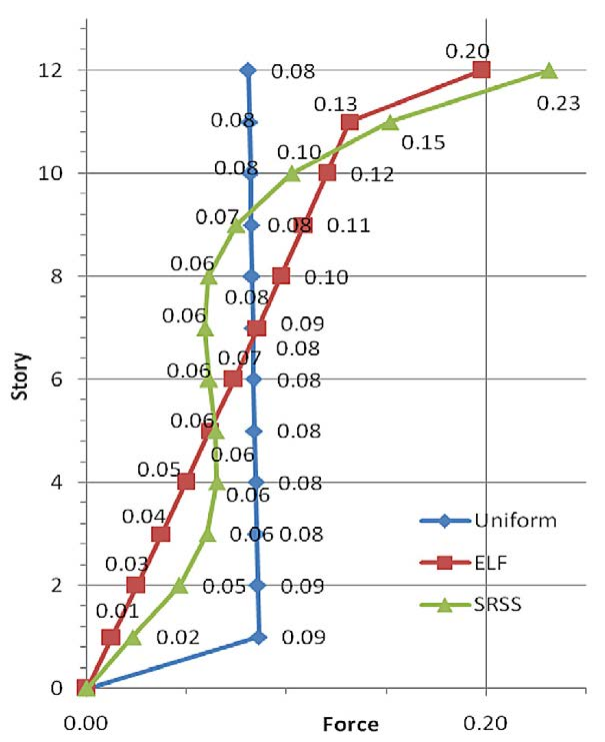

Fig. 4j. FEMA load distribution patterns scheme

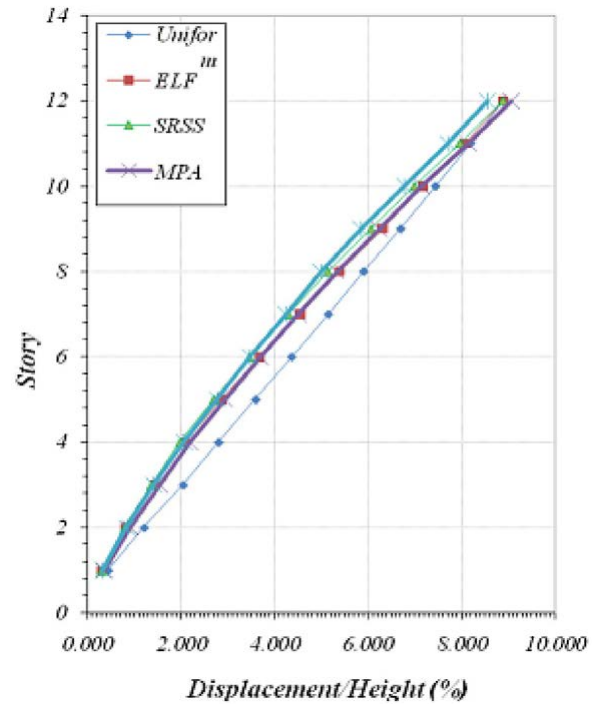

Fig. 4l. Maximum storey displacement from MPA and FEMA estimations

Fig. 4. Analysis results for 12-storey structure 
Table 3. Amounts of building base shear in 12-storey frame by means of MPA estimations (in 3 modes), FEMA, and estimation errors

\begin{tabular}{|c|c|c|c|c|c|c|c|c|}
\hline \multicolumn{5}{|c|}{ Base shear [ton] } & \multicolumn{4}{|c|}{ Error [\%] } \\
\hline \multicolumn{3}{|c|}{ Fema } & \multirow{2}{*}{$\begin{array}{c}\text { MPA } \\
\text { (3 mode) }\end{array}$} & \multirow{2}{*}{$\begin{array}{l}\text { RHA } \\
\text { (Avg) }\end{array}$} & \multicolumn{3}{|c|}{ Fema } & \multirow{2}{*}{ MPA } \\
\hline Uniform & ELF & SRSS & & & Uniform & ELF & SRSS & \\
\hline 245 & 183 & 180 & 251 & 259 & 5 & 29 & 31 & 3 \\
\hline
\end{tabular}

tween structure base shear under different analysis for 12-storey frame is demonstrated.

\section{CONCLUSIONS}

In this paper, the 4-storey frame was considered as short order frame, 8-storey as middle order frame, and 12-storey as a high order frame. According to the assumptions in this study (such as 2-dimensional building, usage of acceleration mappings) and the performed analyses, the following conclusions are achieved:

\section{For short order frames:}

- Regarding the similar function of three distribution load patterns and modal method in estimation of maximum displacement and relative storey displacement it can be deduced that higher modes and the shape of the pattern does not have any effects on the final response; this deduction can be due to the short order nature of the structure.

- For the base shear results, it can be inferred that higher modes have unpleasant effects on response estimation. Moreover, the load distribution figure in SRSS format will achieve better results comparing to ELF and uniform. The performance of FEMA load distribution patterns is relatively appropriate.

2. For middle order frames:

- About FEMA load distribution pattern, the uniform load distribution in relative storey displacement estimation does not have proper performance. Relatively, SRSS load distribution pattern in relative estimation of storey displacement has better performance than ELF load distribution pattern.

- Uniform load distribution does not have proper performance in estimation of the maximum story displacement in lower stories. ELF load distribution pattern comparing to other patterns acts more accurately.

- ELF load distribution can be achieved for relative displacement and maximum displacement of stories on one third of frames with the same accuracy or even better than MPA method. In estimation of relative and maximum story displacement, MPA method has weak performance.

- Considering the base shear results, it can be mentioned that higher modes have unpleasant effects on estimating the response. Moreover, the load distribution scheme in SRSS form will lead to better results comparing ELF and uniform.

3. For high order frames:

- Uniform load distribution pattern in estimation of maximum story displacement of lower stories does not perform properly. ELF load distribution pattern, comparing to other patterns, acts more accurately. The performance of FEMA load distribution patterns in estimating maximum story displacement is unsuitable.

- MPA method, comparing to ELF and SRSS, has weaker performance in estimation of maximum story displacement.

- MPA method, comparing to ELF and SRSS, has much better performance in estimation of maximum base shear.

4. Finally, for all kinds of frames the following conclusions can be made:

- Among the FEMA load distribution patterns, SRSS shows the stories base shear more accurately.

- Uniform load distribution in estimating story displacement, especially lower stories acts unsuitably. ELF pattern comparing to others acts more accurately in response estimation.

- By increasing the frames' height, the responses resulted from load patterns and modal method will differ from each other.

\section{REFERENCES}

1. Driver R.G., Kulak G.L., Elwi A.E., Kennedy D.J.L. 1998. FE and simplified models of steel plate shear wall. Journal of Structural Engineering, 124(2), 121-130. 
2. Timler P.A. and Kulak G.L. 1983 Experimental Study of Steel Shear Walls. Struct. Eng. Rept. 114, Dept. Civil Eng. Univ.Alberta.

3. Kulak G.L., Kennedy L.D.J., Elwi A.E. 1985. Cyclic test of four-story steel plate shear wall. Journal of Structural Engineering, ASCE, 124(2).

4. Berman J. and Bruneau M. 2003. Plastic Analysis and Design of Steel Plate Shear Walls. Structural Engineering, 129(11), November.

5. Bruneau M. and Bhagwagar T. 2002. Seismic retrofit of flexible steel frames using thin infill panels. www.elsevier.com

6. Elgaaly M., Caccese V., Du C. 1993. Postbuckling behavior of steel plate shear walls under cyclic loads. Journal of Structural Engineering, ASCE, 119(2).

7. Elgaaly M. 1998. Thin Steel Plate Shear Walls Behavior and Analysis. Thin-Walled Structures 32, 151-180.

8. Astaneh-Asl A. 2001. Seismic Behaviour and Design of Composite Shear Walls. Steel TIPS Report, Structural Steel Educational Council, Moraga, CA.

9. Sabouri-Ghomi S. and Roberts T.M. 1992. Nonlinear Dynamic Analysis of Thin Steel Plate Shear Walls Including Shear and Bending Deformations. Engineering Structures, 14(5), 309-317.

10. Sabouri-Ghomi S., Carlos E., Ventura M. and Mehdi Kharrazi H.K. 2005. Shear Analysis and Design of Ductile Steel Plate Shear walls. Journal of Structural Engineering, ASCE, June.
11. Appendix M, CSA, Standard-CAN/CSA-S16.194(S16.1) 1994. Canada National Standard for Limit states of steel structures.

12. Seismic provision for Structural Steel Buildings. Including Supplemeny No. 1, March 9, 2005, American Institute of Construction, Inc.

13. Iran National Building Code, 519. Housing and Municipal Engineering Ministry, 2000.

14. Iran National Building Code, Standard 2800. Design of Housing and Municipal in Seismic, 2005.

15. FEMA 2000. NEHRP “Recommended provisions for seismic regulations for new buildings" Report No. 356, Federal Emergency Management Agency, Washington D.C.

16. Applied Projects in Seismic Rehabilitation of Building. Shayanfar M.A. and Ghanoonibagha M. Abnous Publication, Tehran, 2010.

17. ATC, 1996. NEHRP "Guidelines for the seismic rehabilitation of buildings”. Applied Technology Council, Report ATC-40. Redwood City.

18. Chopra A.K. and Goel R.K. 2001. A Modal Pushover Analysis Procedure to Estimate Seismic Demands for Buildings: Theory and Preliminary Evaluation. Pacific Earthquake Engineering Research Center College of Engineering, PEER Report 2001/03.

19. Chopra A.K. and Goel R.K. 2002. A modal pushover analysis procedure for estimating seismic demands for buildings. Earthquake Engineering and Structural Dynamics, 31, 561-582. 